\title{
RESTAURACION DEL REAL COLISEO DE CARLOS III, EN SAN LORENZO DE EL ESCORIAL, MADRID-ESPAÑA
}

\author{
(RESTORATION OF THE REAL COLISEO DE CARLOS IIIEL ESCORIAL/MADRID/SPAIN)
}

Mariano Bayón y José Luis Martin Gómez, Arquitectos

146-97

\section{RESUMEN}

La restauración del Real Coliseo de Carlos III en San Lorenzo de El Escorial puede interesar no sólo como realización en si misma sino también como precedente en esta clase de actuaciones, teniendo presentes siempre sus circunstancias concretas tanto históricas como artisticas (s. XVI: el Monasterio; s. XVIII: Carlos III, el Barroco...) y el proceso posterior de abandono, sustitución, destrucción, etc. sufrido por el edificio.

Las tareas de restauración son dificiles por lo que entrañan de búsqueda en el pasado sin intentar alterarlo. Existen distintas posiciones frente al hecho de la restauración pero, pese a todas las buenas intenciones, hemos continuado asistiendo a la irresponsable destrucción del patrimonio histórico.

El entorno del edificio, su enclave, su ambiente, etc., determinaron, en este caso, una solución precisa y escueta, que diese respuesta a la necesitada memoria colectiva.

\section{SUMMARY}

The restoration of the Real Coliseo de Carlos III in El Escorial is an interesting work not only by the realization proper but also as a precedent in this kind of actions, allways bearing in mind its peculiar circumstances both historical and artistic (16th century: The Monastery; 18th century; Charles the 3rd, the Baroque...) and later neglecting process, substitution, destruction, etc. that the building has suffered.

The works for restoration are difficult as they involve a search in the past but without alter it. There are different positions from this fact, but in spite of all good intentions, we have assisted to an irresponsible destruction of this historic heritage.

The situation of the building, its surroundings, its ambience, etc. have determined in this case the precise and simple solution that must give a response to the colletive memory.

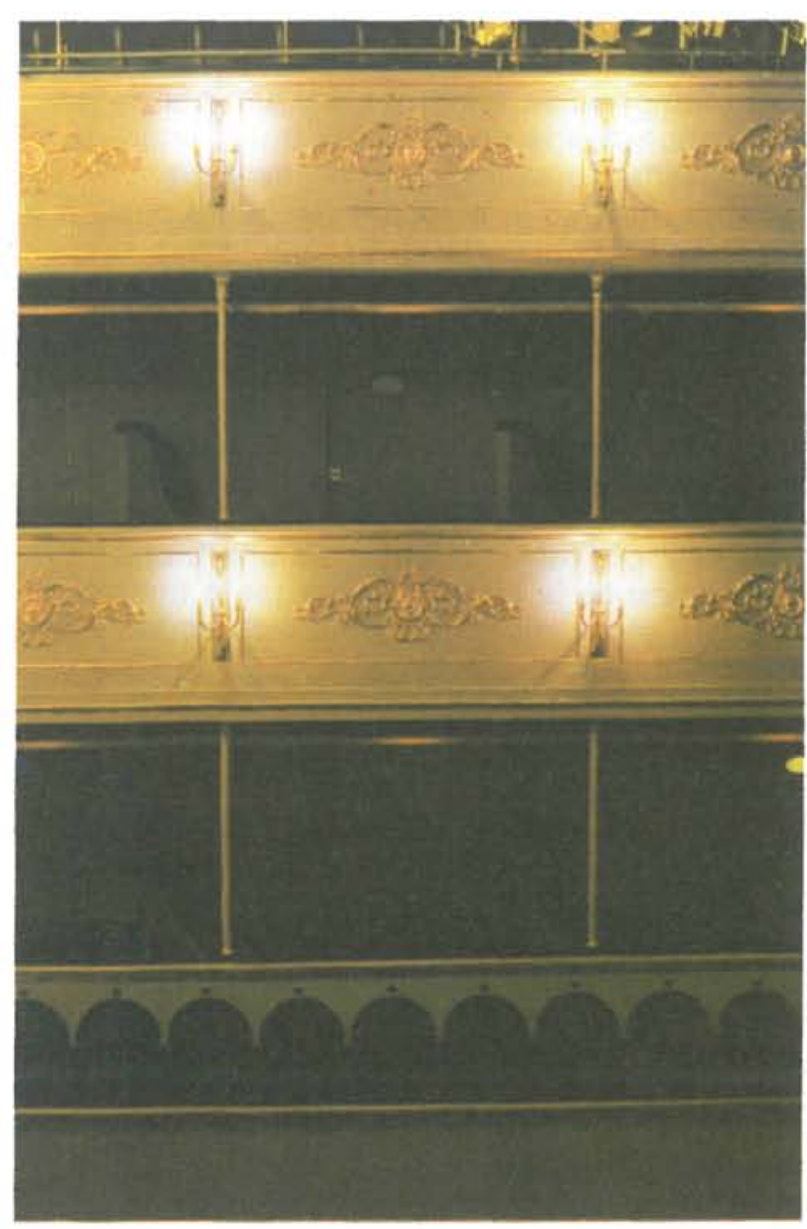

Desde bien avanzada la obra nos hemos dado cuenta de que la formulación de nuestra forma de trabajo contrastaba claramente con otras interpretaciones del trabajo de restauración.

La verdad es que, una vez acabada, y sobre todo en el momento en que se nos concede el Premio Nacional de Restauración, junto con otros tres trabajos más, parece aclararse una cierta polémica, más o menos oculta en torno al tema. Y para ello se podian leer los criterios del jurado español a la hora de designar los premios.

La polémica estaba ya planteada y en el fondo de los trabajos. Lo que ocurre es que, al darse cada vez más importancia a los temas de restauración, reutilización, revitalización y construcción en históricos o conjuntos construidos de gran fuerza y unidad, existentes en gran cantidad en nuestro pais, se va haciendo necesario hablar de ellos y fijar ideas.

No seremos nosotros, sin embargo, quienes apoyemos la postura de fijar conceptos para hacer "moralidad" de los mismos, es decir, para establecer la rigidez de lo blanco o lo negro, de lo bueno o lo malo, de lo ortodoxo y lo heterodoxo. Se podria decir, generalizando, que en esa condición binaria y maniquea de la 


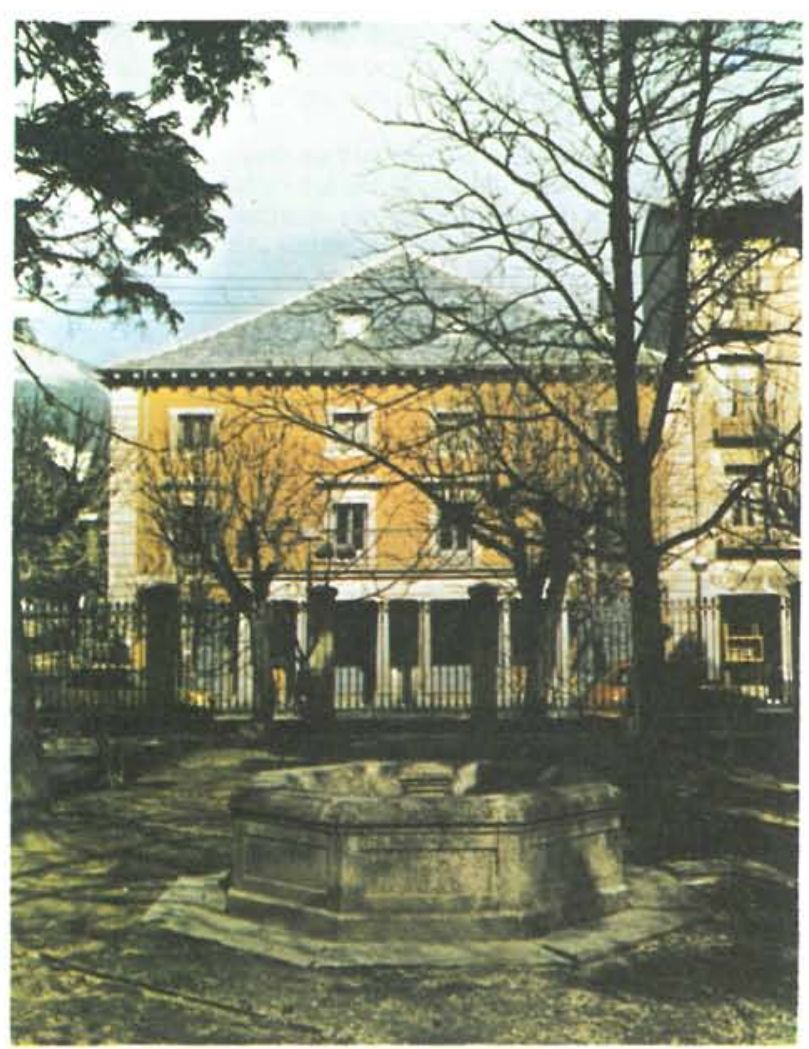

existencia, se pierde lo mejor de la riqueza y la diversidad de la actividad humana.

Ya decimos que casi nos hemos visto obligados a tomar postura después de ejecutada la obra, lo cual es, como poco, una pérdida de tiempo, un esfuerzo innecesario.

Explicaremos, en pocas palabras en qué consiste a nuestro entender, la polémica de la restauración. Por lo menos, la polémica actual, ya que en cada momento ha habido una motivación polémica distinta para este tema (como para cualquier otro tema, como es lógico, ya que los conceptos sobre las cosas se van modificando en el tiempo en parte urgidos por las nuevas cosas inventadas, en un ir y venir del Dr. Frankenstein a su producto y al revés).

La polémica está, en esquema, en si se debe o no reflejar por contraste lo actuado en restauración de lo que se mantiene, lo que se restaura de lo que se conserva.

Y esta simple cuestión, al parecer nimia, atrae encendidos fervores a favor y en contra de una $\mathrm{u}$ otra tendencia.

En la realidad el problema plantea algunas facetas más o menos complejas, es decir, no es tan esquemático, aunque bien se pudiera considerar de la forma expuesta.

No es tampoco un tema ocioso, por cuanto de su enfoque puede depender el tratamiento de tanta y tanta restauración o renovación histórica, incluso la elección del gasto público y sus tipos en esta materia. Porque la decisión de la polemica y su trasfondo orienta o puede orientar la política patrimonial.

No es por tanto sólo un tema de especialistas, un tema criptico o cerrado, y en este sentido se puede decir que el profundo enfoque del dilema está presente en una $u$ otra concepción de la historia y, por tanto, también en una u otra concepción de la historia, y por tanto también en una u otra concepción de la actualidad y sus ingredientes.

\section{Nos explicaremos.}

Reflejar por contraste lo actuado en restauración respecto de lo que se conserva es ponderar el sentido simbólico de la historia respecto de su valor en uso. Es decir, que si de un edificio lo que se pretende obtener en su "reciclaje histórico", es decir su auténtico uso como edificio útil en su componente de edificio histórico, entonces lo que se habrá de conseguir será su recuperación histórica completa, aún cayendo en la mentira piadosa de reconvertir parte de él para el total 
alojamiento de su uso recuperado. Un uso recuperado es también el uso sentimental afectivo o monumental en el sentido de la "memoria" colectiva.

Si, por el contrario, el edificio se restaura fundamentalmente para "ser visto" y menos para ser "usado", aqui encajará con más facilidad la vanidosa tarea, no siempre carente de atractivos creativos, de marcar la impronta diferenciadora del proceso, no ya sólo con nuevas técnicas y nuevas formas, sino incluso con nuevos conceptos.

Este último sentido para con los edificios históricos, es decir, el concepto del señalamiento de lo actuado respecto de lo no actuado se basa en la suposición de que la forma de la arquitectura y del diseño actuales
La historia se queda como simbolo, y al mismo tiempo queda intacta. La nueva actuación es la nueva historia del edificio. Se cree y se respeta la historia. Se crea una nueva historia sin tocar la anterior.

El concepto de la no separación de lo actuado respecto de lo conservado se basa fundamentalmente en la revitalización del edificio, en su "reciclaje" total de uso como de los aspectos sentimentales o recordativos. Lo que importa aqui es la nueva asunción del edificio por la colectividad a que pertenece. No interesa, por tanto, hacer triunfar la vocación imaginera del autor (puede llamarse a aquélla con más propiedad "restauración de autor»), sino hacer triunfar la imagen recompuesta del edificio no para ser mostrada sino para volver a producir los mismos efectos que para los que

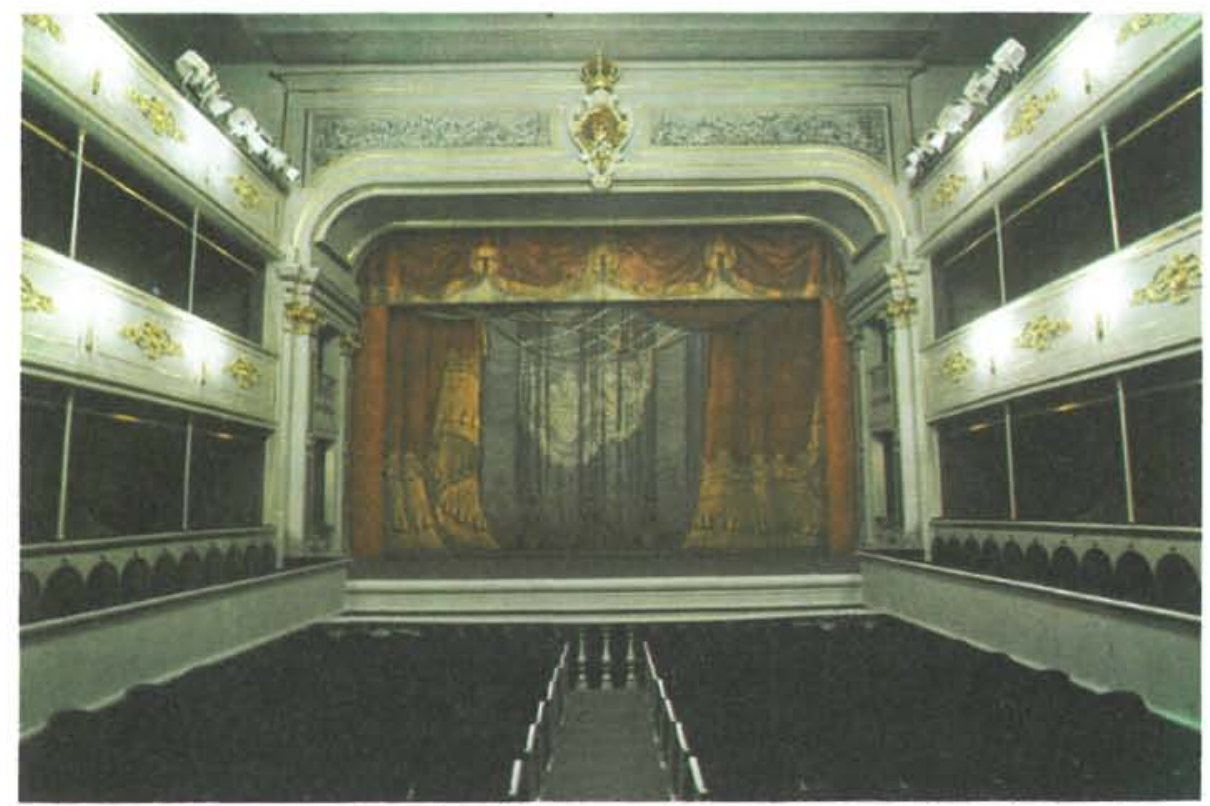

es tan fuerte y tan clara como para estar obligados a evitar su contaminación estilistica.

Sin duda que este enfoque proviene del Movimiento Moderno y su seguridad en si mismo y en el futuro. Coincide con una voluntad ingente de la búsqueda de una forma transmisible, racional, y generalizable, internacional. Voluntad que ha demostrado hoy estar basada más en la ilusión que en la práctica, al menos en muchos sectores tanto de la vida cotidiana como de los sentimientos. Esta es la opinión, la teoria, del Movimiento Moderno respecto de la restauración: señalamiento, separación, signos, contrastes. No sólo de la restauración, también de la insurgencia de la nueva arquitectura en la ciudad con contexto formal o histórico muy establecido y decantado. fue creada, o los nuevos de su reutilización en el caso en que el nuevo uso pueda ser asumido sin traumas por el edificio restaurado.

Este sentido restaurador, el sentido de la nueva vida insuflada por el arreglo, y la recomposición, no cree en la historia. Sólo cree en ella como algo que tiene el valor único de uso, con capacidad de poderse actuar sobre ella, superponerse, modificarse o interpretarse. Seria tan dificil separar estratificadamente en puridad el paso del tiempo... ¿Qué quedaria de la catedral de Toledo en una teoria de "limpieza" a la búsqueda de lo originario? ¿Quizás sólo la capilla Mozárabe? Es el caso de la reciente y más que dudosa "limpieza» de las murallas de Lugo de sus ricas y complejas "adherencias" posteriores a su edificación. Es, en fin, un sentido que evitando el "voyeurismo" 


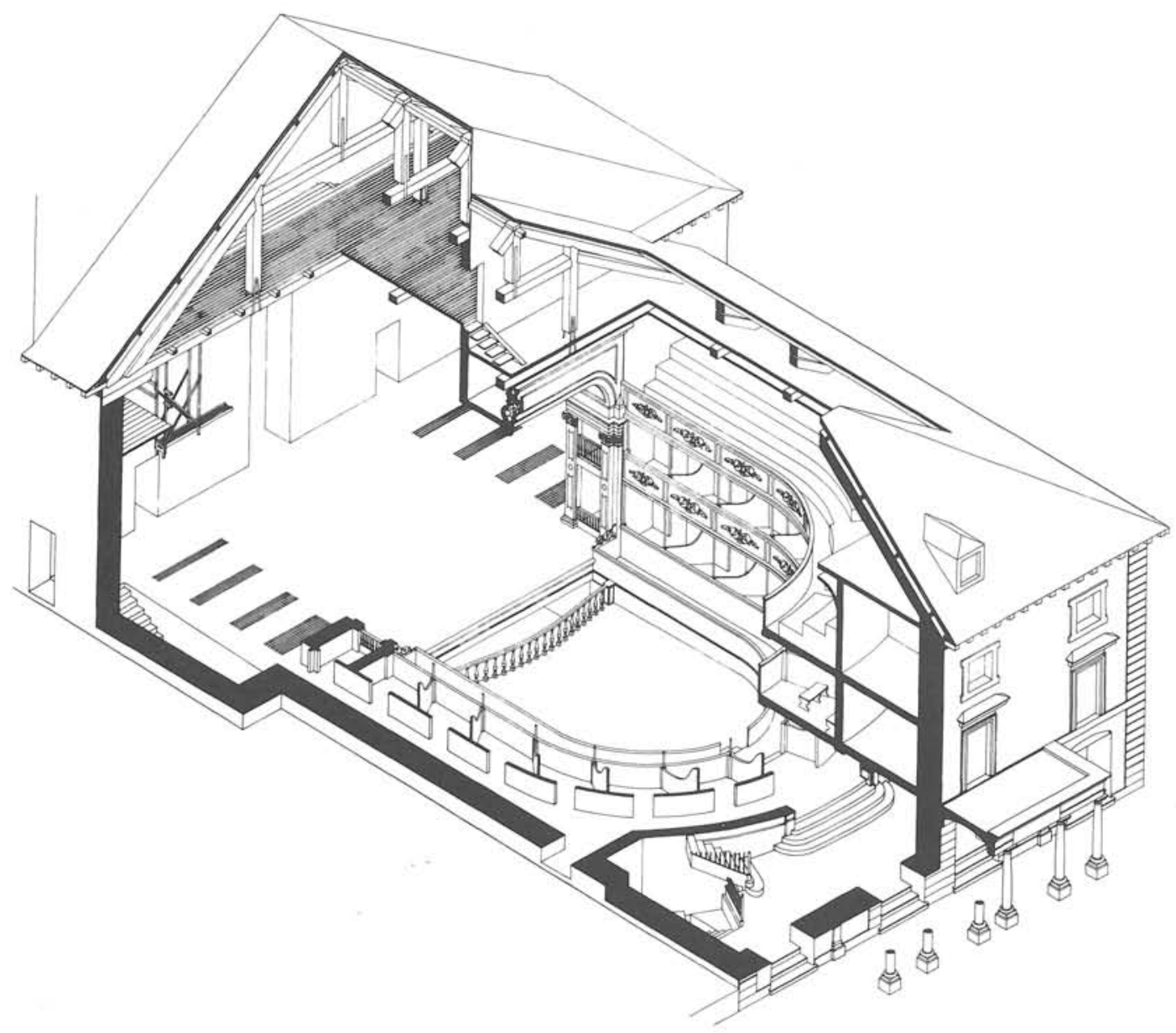

histórico, utiliza la historia al servicio de la práctica, de la memoria, del sentimiento, de la conciencia comunitaria... aceptando sin pudor los remiendos, superposiciones y "huellas" que denotan el paso del tiempo por el monumento. Para este concepto no hay mejor pago que la vida resucitada por la restauración.

Pero, ¿quién puede creer en la existencia de una única verdad con una sola forma externa? La rigidez de cualquier planteamiento, como deciamos, reduce la libertad de la elección.

¿Cuál es la solución al dilema? Como en muchos casos la solución del dilema está en la supresión de los interrogantes: descansar en la duda. Simplemente actuar. En cada caso la solución será una. $Y$ dentro de cada caso, habrá posibilidades de actuar de formas distintas a la vez, o no. Depende. Los problemas entran al intentar generalizar.

Es éste un tema, como el de la arquitectura en general cuyos problemas de adecuación (y otros muchos) no se resuelven más que con sensibilidad. Esa es la dificultad de hacer cumplir ordenancistamente la calidad de la imagen urbana. Cuanto menor es la escala de una actuación, más se echa en falta la necesidad de una sensibilidad.

Esta palabra, sensibilidad, ha estado y está comúnmente ajena (para muchos es causa aún de una cierta vergüenza) a la teoria y a la práctica arquitectónica, aunque subyace en gran medida en ellas en la realidad. Hubo un momento en que la ilusión de racionalizar ambas, de obtener un método cientifico para usarlas, estuvo en todas las mentes, pero la desilusión y el fracaso parecen que van dando lugar a la duda y con ella a la libertad y la experimentación.

Por eso, por partir de la acción como sistema, estas convicciones han surgido del análisis de la obra acabada y no de hipótesis algunas previas al comienzo de la misma. Las soluciones vinieron, se encontraron, pero no estaban deliberadas y definitivamente previstas desde el comienzo. No habia teoria, habia la 
contigencia de ciertos acontecimientos que iban delimitando la acción, estaba un edificio, un entorno, un enclave, unas perspectivas y unos datos existentes bajo las adherencias, las sustituciones, los repintados, los retelados. Habia un grupo humano y unos recuerdos, unas ilusiones y unas necesidades, unas economias y un tiempo. $Y$ con todo ello se recompuso una actuación hecha de todo ello, de forma contingente, aunque con la seguridad de que no seria la única forma posible de efectuarla.

Las obras de restauración han consistido básicamente en las siguientes:

\section{EXTERIORMENTE}

- Arreglo general de cubiertas.

- Edificación de un pórtico con columnas en la fachada principal, recuerdo del paso antiguamente existente que cruzaba la calle de Floridablanca. Este pórtico es tema repetido en la arquitectura de Juan de Villanueva, de Italia como del resto de Europa, habiéndose sustituido en el caso del Escorial por el pórtico atravesado que hemos comentado.

- Pintura general de fachadas con el color coincidente con las últimas capas de pintura encontradas (las casas de oficios fronteras al teatro estaban también pintadas del mismo color. Los desconchones de los enfoscados posteriores asi lo denuncian).

- Reposición y pintura de aleros.

\section{INTERIORMENTE}

- Refuerzo de los apoyos de las vigas triangulares de cubierta que en su unión con los muros perimetrales se encontraban destruidos.

- Refuerzo de muros en las zonas más dañadas.

- Aprovechamiento parcial de la cubierta del edificio como zona de biblioteca del teatro.

- Aprovechamiento del patio de butacas para la excavación de un espacio destinado a "parnasillo" del teatro: el llamado "La Comedia Nueva o El Cafè", en honor a Leandro Fernández de Moratin, por ser éste un espacio idéntico al que desarrolla la acción de la citada obra.

- Excavación y aprovechamiento para camerinos en la zona bajo el escenario.

- Recalce de elementos de proscenio.

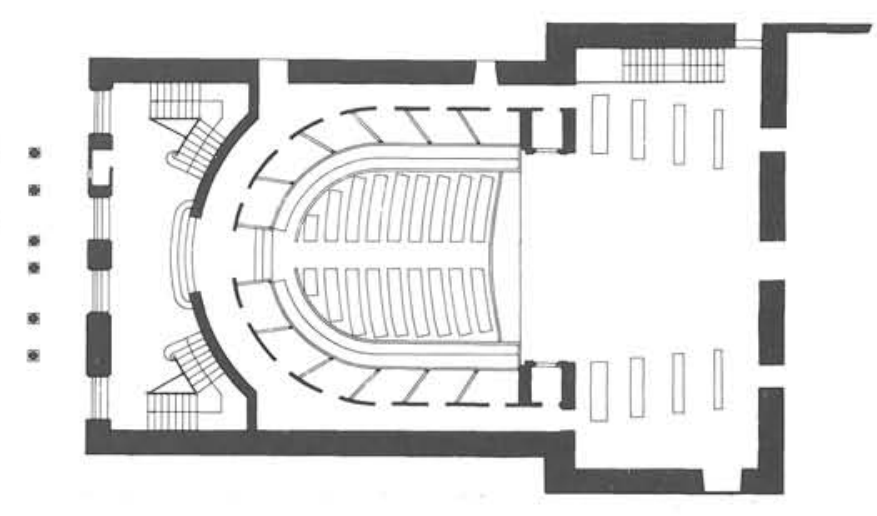

PLANTA BAJA. Acceso.

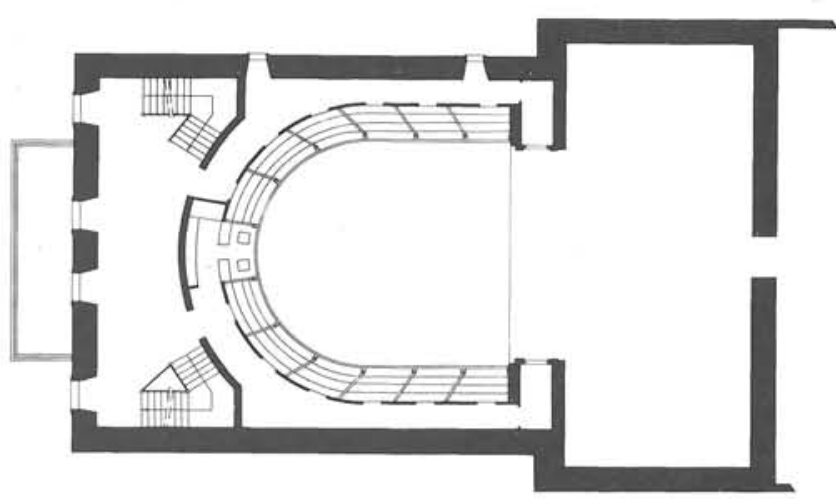

PLANTA PRIMERA. Palco Real.

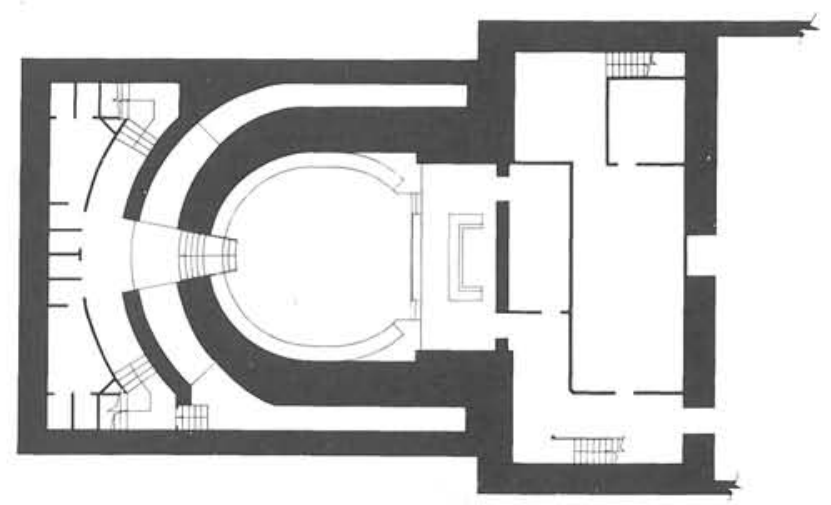

PLANTA SOTANO. Café.

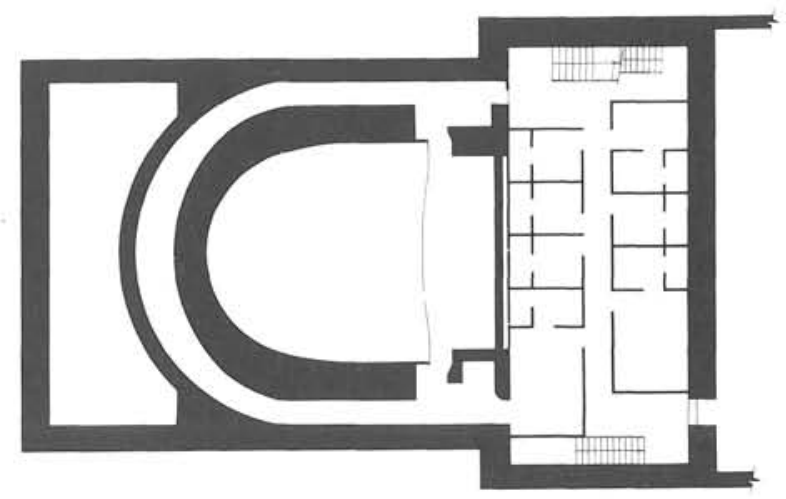

ENTREPLANTA. Camerinos. 

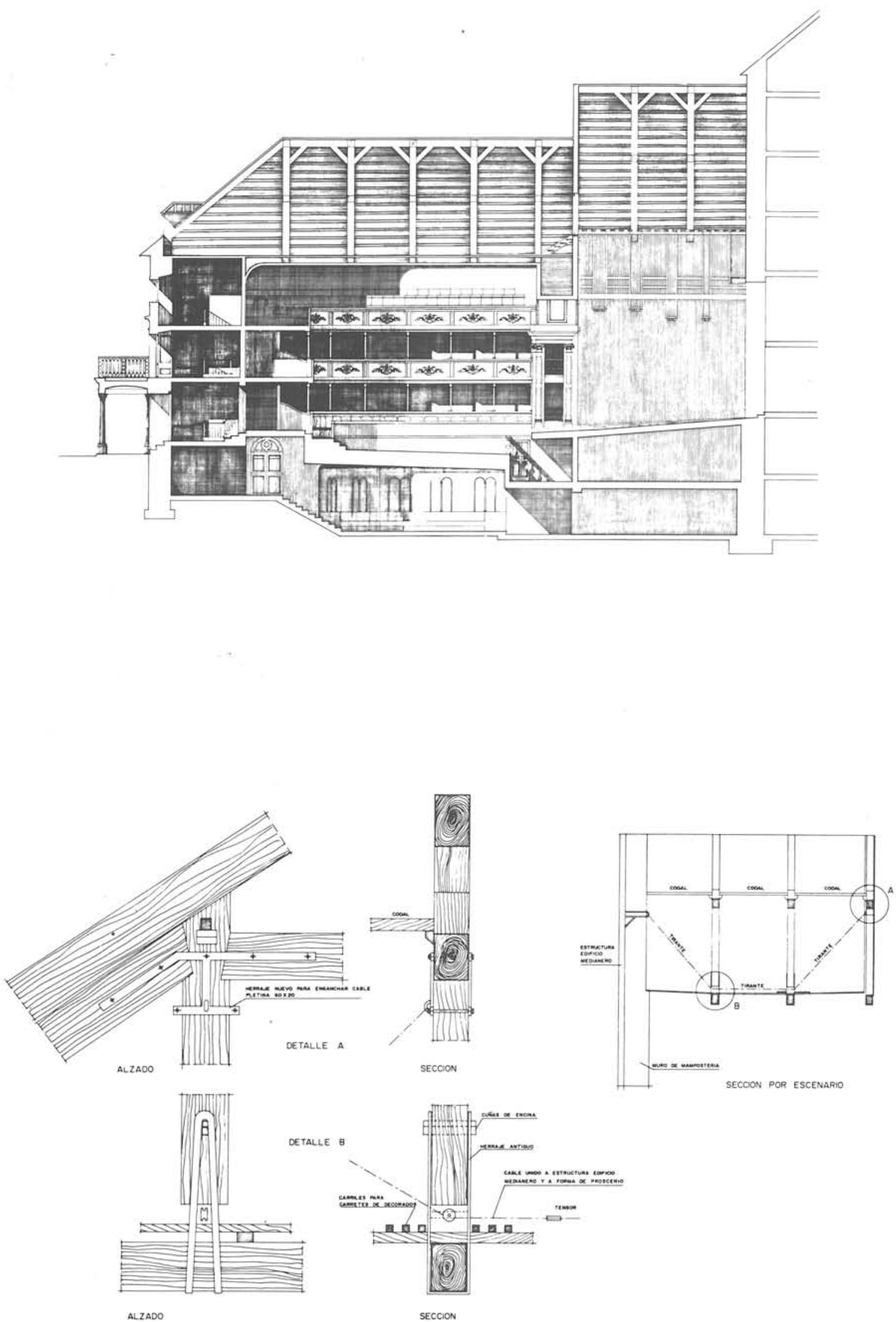

DETALLE PARA EL VANO EN FORMAS DE ESCENARIO 

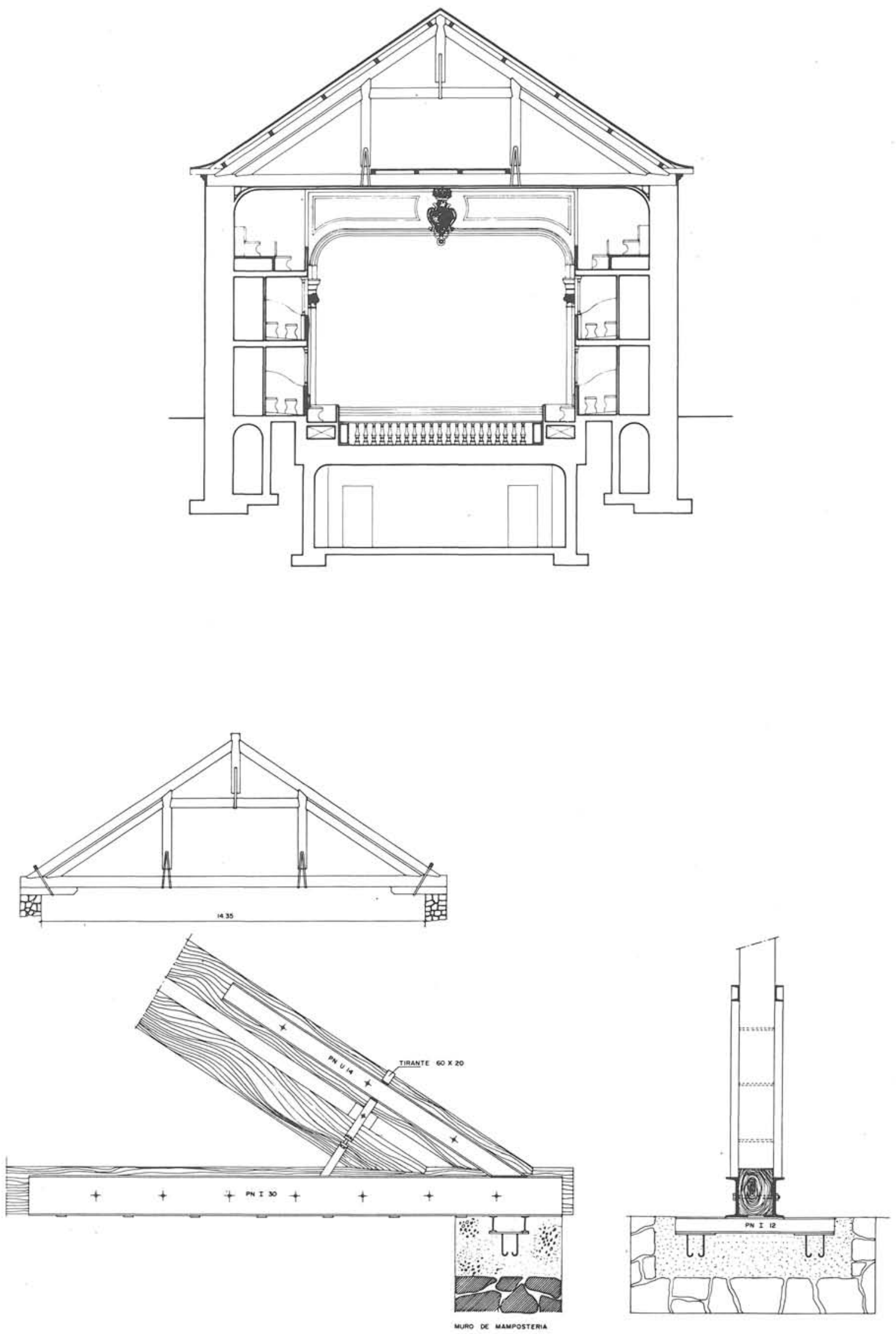

DETALLE DE APEO

FORMAS DE SALA 


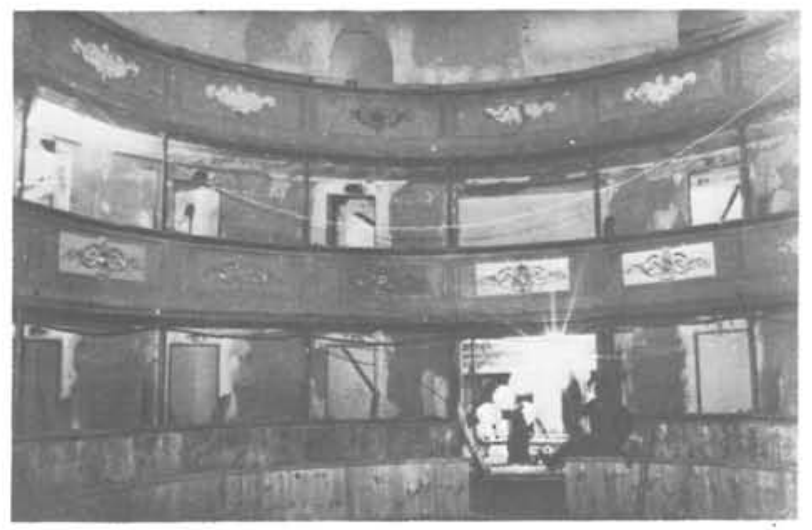

MEMORIA DE LA MADERA QUE SE NECESITA PARA EL TEATRO DEL REAL SITIO DE SAN LORENZO

\begin{tabular}{|r|r|}
\hline \multicolumn{1}{|c|}{ Medias Varas } & Diez y cuarto \\
6 de $\ldots .40$ pies & 2 de $\ldots .40$ pies \\
18 de $\ldots \ldots$ & 63 de $\ldots .27$ \\
11 de $\ldots .30$ & 4 de $\ldots .24$ \\
8 de $\ldots \ldots 28$ & 12 \\
12 de $\ldots \ldots 27$ & \\
3 de $\ldots \ldots 25$ & \\
29 de $\ldots \ldots 21$ & \\
8 de $\ldots .20$ & \\
95 & \\
\hline
\end{tabular}

\begin{tabular}{|r|r|r|}
\hline \multicolumn{1}{|c|}{ TERCIAS } & \multicolumn{1}{c|}{ SESMAS } \\
6 de $\ldots 40$ pies & 70 de $\ldots .42$ pies \\
2 de $\ldots .38$ & 4 de $\ldots .39$ \\
3 de $\ldots .36$ & 4 de $\ldots .36$ \\
20 de $\ldots .33$ & 4 de $\ldots .33$ \\
3 de $\ldots .31$ & 6 de $\ldots .31$ \\
16 de $\ldots .30$ & 55 de $\ldots .30$ \\
11 de $\ldots .28$ & 2 de $\ldots .28$ \\
6 de $\ldots .27$ & 12 de $\ldots .27$ \\
3 de $\ldots .26$ & 88 de $\ldots .25$ \\
17 de $\ldots .25$ & 7 de $\ldots .24$ \\
18 de $\ldots .24$ & 2 de $\ldots .22$ \\
10 de $\ldots .21$ & 24 de $\ldots .21$ \\
62 de $\ldots .18$ & 2 de $\ldots .20$ \\
177 & & 280 \\
\hline
\end{tabular}
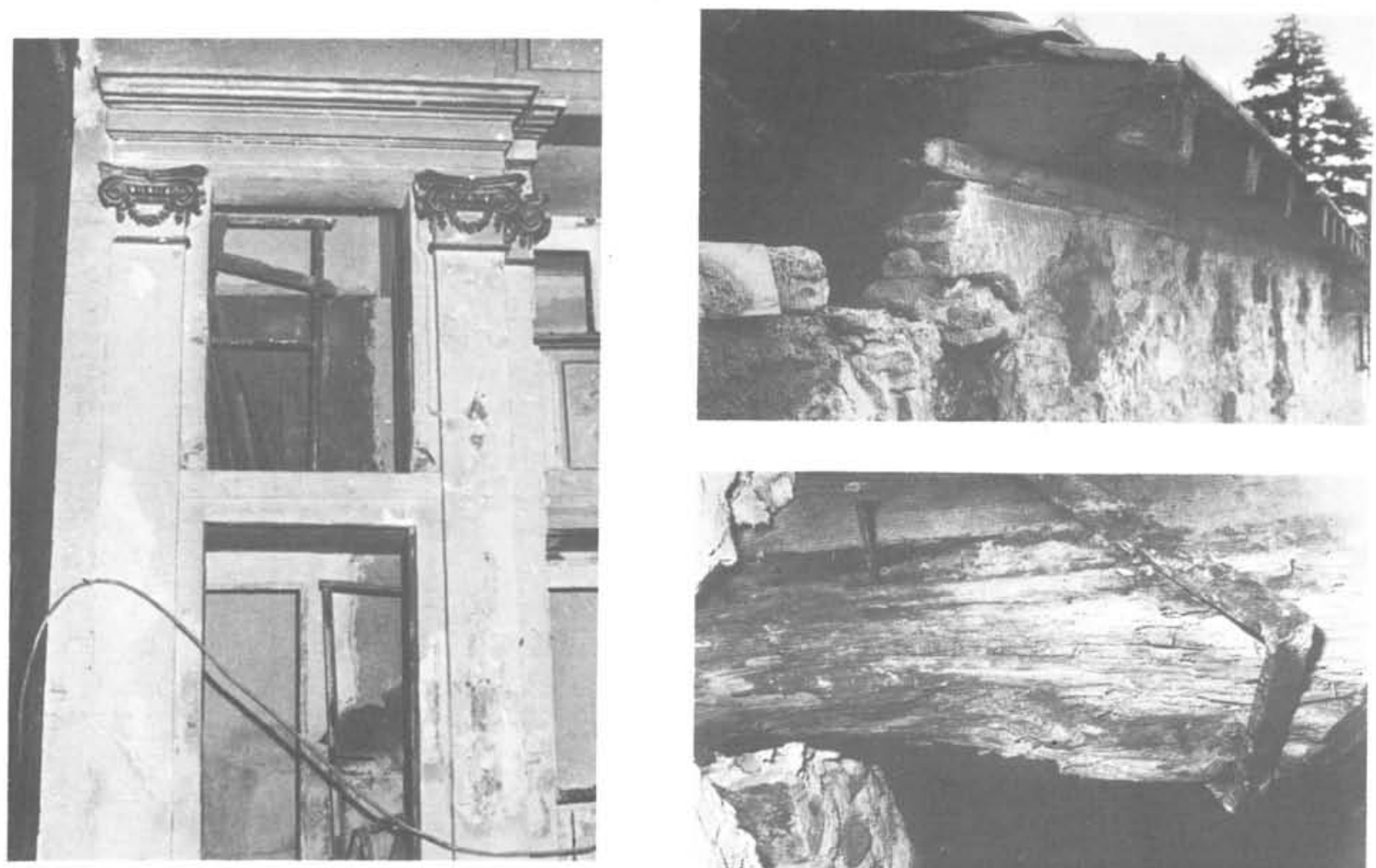

Situación inicial.

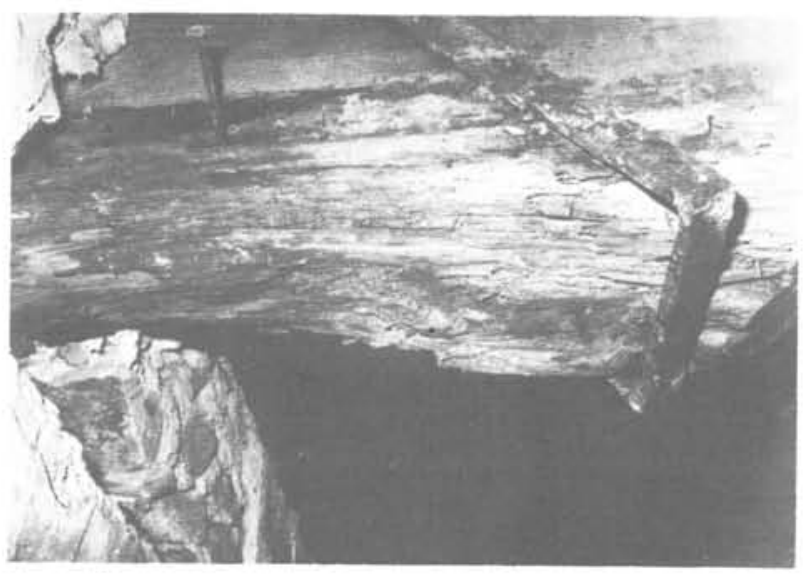

Cornisa y apoyo de formas. 


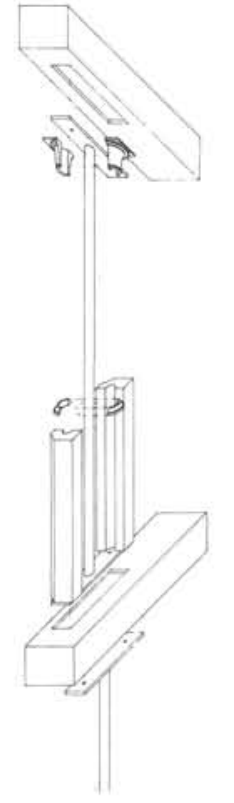

Descomposición constructiva de una de las columnillas de sujeción de los palcos del Coliseo. compuestas por un eje macizo de hierro forjado al que se le adosan elementos estructurales y decorativos de madera.

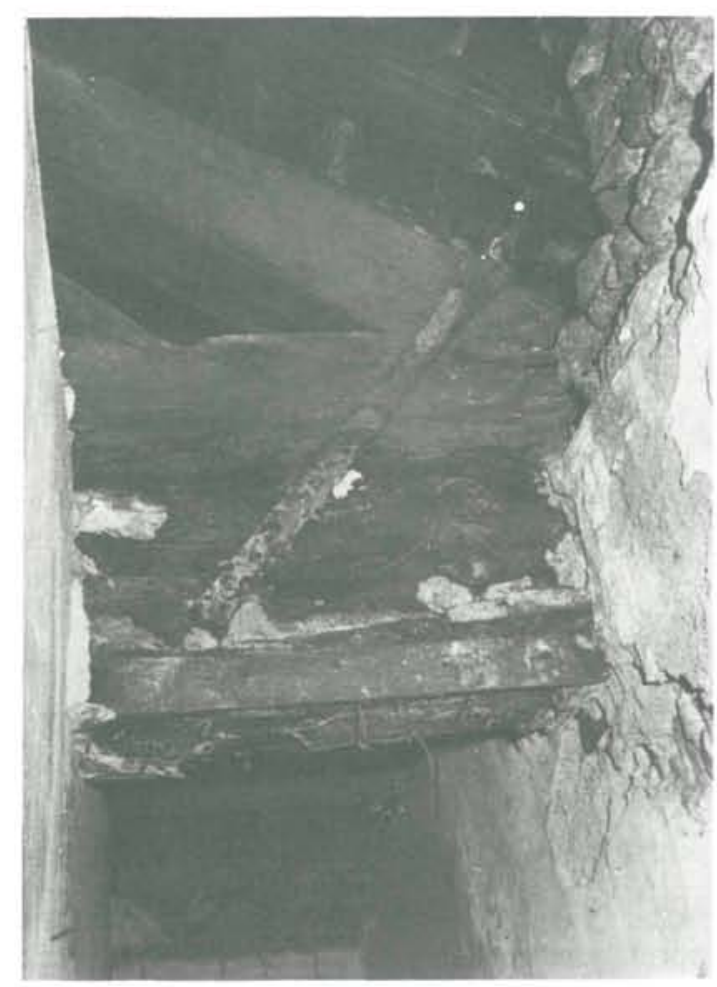

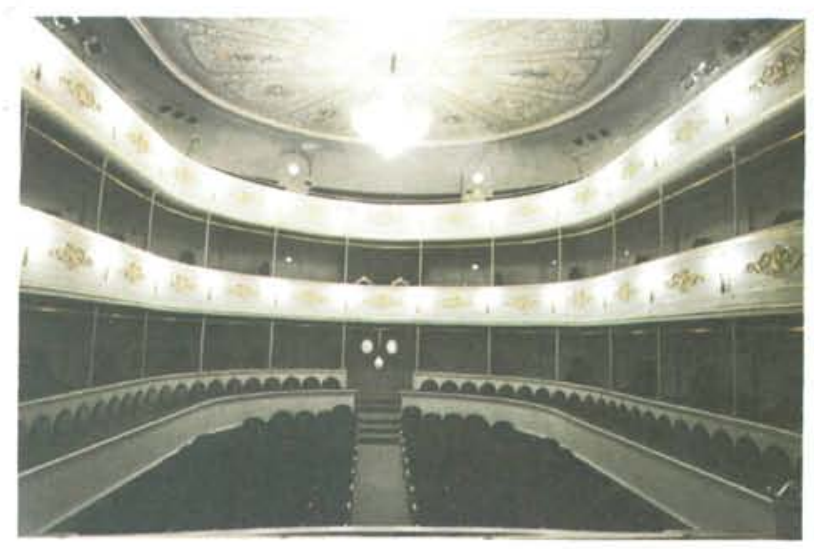

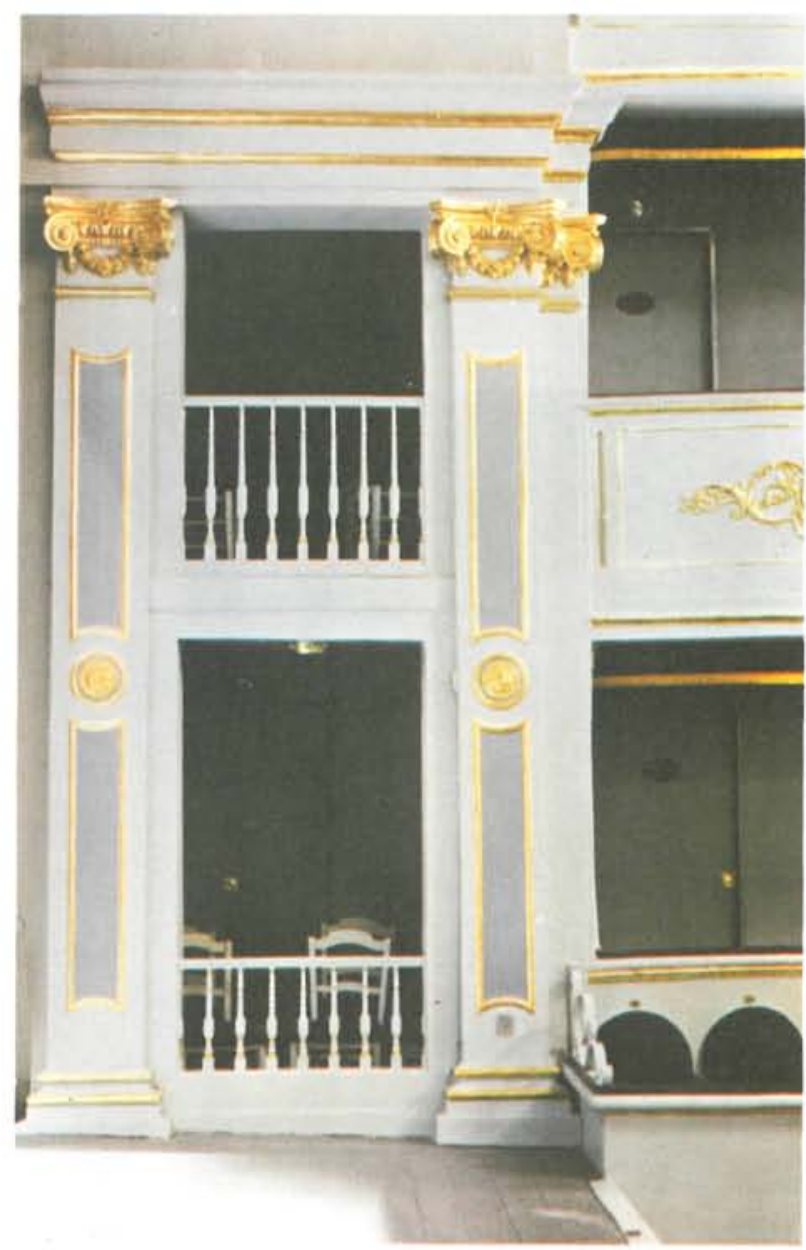

Situacion actual. 

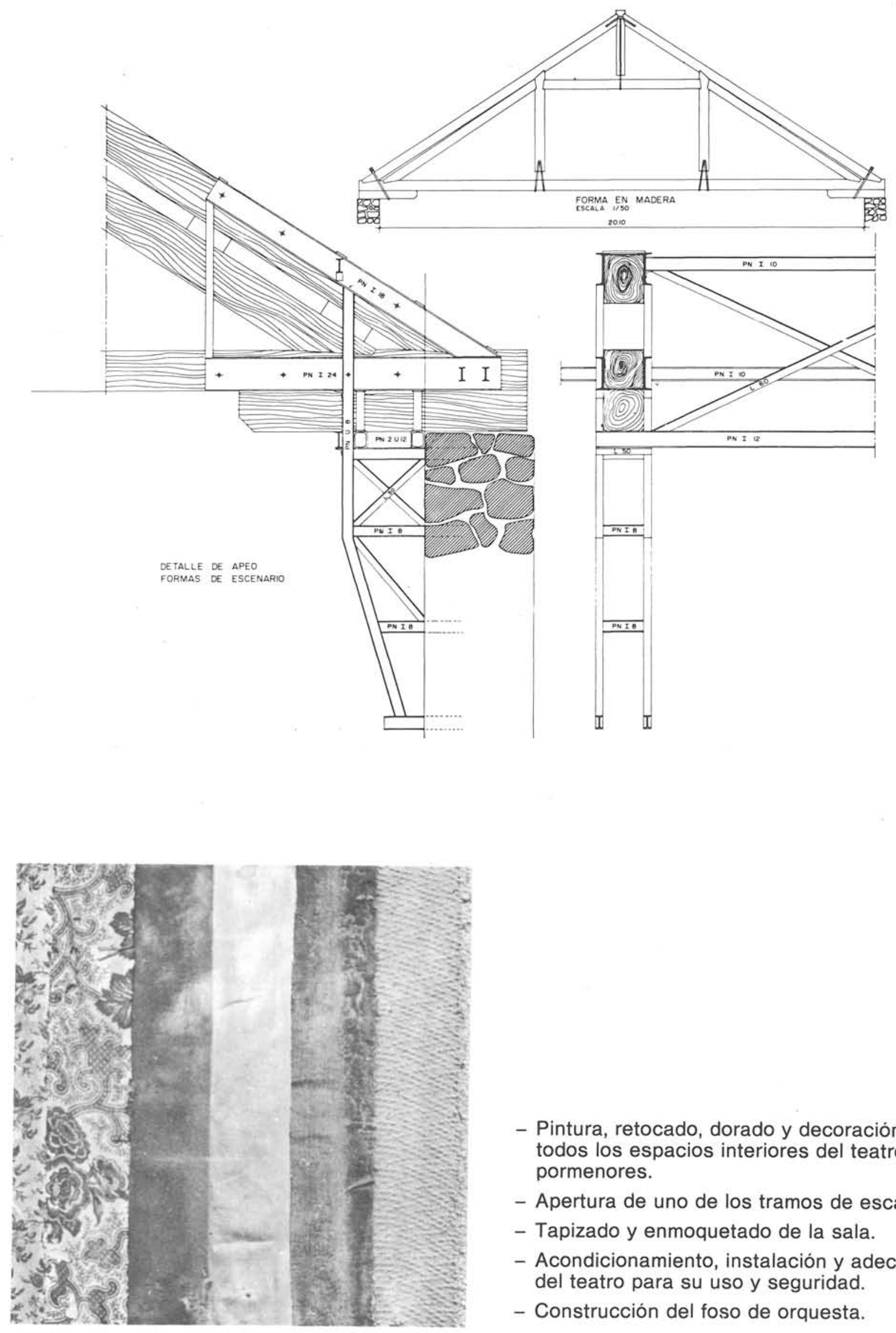

- Pintura, retocado, dorado y decoración de todos los espacios interiores del teatro y sus pormenores.

- Apertura de uno de los tramos de escalera.

- Tapizado y enmoquetado de la sala.

- Acondicionamiento, instalación y adecuación del teatro para su uso y seguridad.

Tapices.

- Construcción del foso de orquesta. 